\title{
Hesperidin Ameliorates Immobilization-Stress-Induced Behavioral and Biochemical Alterations and Mitochondrial Dysfunction in Mice by Modulating Nitrergic Pathway
}

\author{
G. L. Viswanatha, ${ }^{1}$ H. Shylaja, ${ }^{1}$ K. S. Sandeep Rao, ${ }^{2}$ V. R. Santhosh Kumar, ${ }^{3}$ and M. Jagadeesh ${ }^{4}$ \\ ${ }^{1}$ Department of Pharmacology, PES College of Pharmacy, Bangalore 560050, India \\ ${ }^{2}$ Biomedical Research Centre, Sheffield Hallam University, Sheffield S11 OW, UK \\ ${ }^{3}$ Department of Pharmacology, Al-Ameen College of Pharmacy, Bangalore 560027, India \\ ${ }^{4}$ Department of Biochemistry, Jayadeva Institute of Cardiovascular Sciences and Research, Bangalore 560069, India
}

Correspondence should be addressed to G. L. Viswanatha, glv_000@yahoo.com

Received 12 November 2011; Accepted 20 December 2011

Academic Editors: V. C. Abilio and S. Tsuruoka

Copyright ( 2012 G. L. Viswanatha et al. This is an open access article distributed under the Creative Commons Attribution License, which permits unrestricted use, distribution, and reproduction in any medium, provided the original work is properly cited.

\begin{abstract}
The present study was aimed to evaluate the protective effect of hesperidin against immobilization-stress-induced alterations in biochemical, behavioral, and mitochondrial functions in mice. In many instances neuroscientists have reported that acute immobilization stress for $6 \mathrm{~h}$ resulted in anxiety and impaired locomotor activity due to excess oxidative-nitrergic stress, depletion of antioxidant defense mechanisms, and mitochondrial dysfunction in animals. In the present study, $6 \mathrm{~h}$ of acute immobilization stress had significantly altered the behavioral (anxiety and memory) and biochemical parameters coupled with mitochondrial dysfunction in Swiss albino mice. Fourteen days of pretreatment with Hesperidin (50 and $100 \mathrm{mg} / \mathrm{kg}$, p.o.) significantly and dosedependently inhibited the behavioral and biochemical alterations and mitochondrial dysfunction caused by acute immobilization stress. Furthermore, pre-treatment of L-arginine $(50 \mathrm{mg} / \mathrm{kg}$, i.p.), a nitric oxide precursor, reversed the protective effect of Hesperidin $(50$ and $100 \mathrm{mg} / \mathrm{kg})(P<0.05)$. In contrast, pretreatment of L-NAME $(5 \mathrm{mg} / \mathrm{kg}$, i.p. $)$, a nitric oxide synthase inhibitor, potentiated the protective effect of Hesperidin $(P<0.05)$. These results suggest the possible involvement of nitrergic pathway in the protective effect Hesperidin against immobilization-stress-induced behavioral, biochemical, and mitochondrial dysfunction in mice.
\end{abstract}

\section{Introduction}

Stress is a very crucial factor in the maintenance of health and disease [1]. Stress induces changes in emotional behavior and anxiety like state, which are associated with oxidative damage, that is, free radical damage $[2,3]$. Acute immobilization stress triggers numerous cellular cascades that lead to increase in ROS production [4]. Because of the brain high oxygen consumption, abundant lipid content, and relative paucity of antioxidant enzymes, the central nervous system is highly vulnerable to free radical damage [5]. Immobilization stress has also been reported to induce 2-3-fold higher rise of plasma cortisol level; increased cortisol level has been linked with anxiety-like behavior $[6,7]$. It is been reported that stress triggers the motor alteration in different animal models and central nucleus of amygdala is important in modulating affective response to stress [8-10].

Natural products such as bioflavonoids possess very good antioxidant property [11] and inhibit lipid peroxidation in biological membranes [12]. Hesperidin is a such natural bioflavonoid that possesses very good antioxidant property [11] and it has been proved to be very effective in various neurobehavioral diseases [11, 12].

With this background, the present study was designed to investigate the possible neuroprotective effect of Hesperidin against acute immobilization-stress-induced anxiety-like behavior and associated oxidative damage in mice. The functional interaction of Hesperidin with nitrergic signaling was investigated using nitric oxide precursor, L-arginine, and nonselective nitric oxide synthase inhibitor, $N(G)$-nitro-Larginine methyl ester (L-NAME). 


\section{Materials and Methods}

2.1. Drugs and Chemicals. Hesperidin, $\mathrm{L}$-arginine, and $\mathrm{L}^{-}$ NAME were purchased from Sigma Aldrich (Bangalore); all other drugs and chemicals used for the study were of analytical grade and purchase from local firms.

2.2. Animals. Male Swiss albino mice weighing 20-25 g were purchased from Bioneeds Preclinical Services, Nelamangala, Bangalore. They were housed under standard laboratory conditions and maintained on $12 \mathrm{~h}$ light/dark cycle and had free access to food and water. Animals were acclimatized to laboratory conditions before the experiment. Each group consists of 10 animals each. All the experiments were carried out between 9:00 am and 17:00 pm. The experimental protocols were approved by Institutional Animal Ethics Committee of PES College of Pharmacy, Bangalore, India (no. PESCP/IAEC/06/2006-07) and conducted according to the committee for the purpose of control and supervision of experimentation on animals (CPCSEA) guidelines for the use and care of experimental animals.

2.3. Treatment Schedule. The suspension of Hesperidin in $0.5 \%$ CMC (carboxy methyl cellulose) in distilled water, LNAME, and L-arginine in normal saline was freshly prepared and administered $10 \mathrm{~min}$ before Hesperidin treatment (50 and $100 \mathrm{mg} / \mathrm{kg} /$ day, p.o.). All the treatments were given once daily for two weeks and animals were subjected to immobilization stress on the 15th day (Figure 1).

2.4. Immobilization Stress. On the 15th day all the animals (except naïve) were immobilized for $6 \mathrm{~h}$ by taping all the four limbs on a board, after putting them on their backs using zinc oxide hospital tape. Release was affected by unraveling the tape after moistening with acetone in order to minimize pain or discomfort. In unstressed group, the mice were kept in animal cage with soft bedding in the experimental room [13].

\subsection{Behavioral Assessments}

2.5.1. Measurement of Locomotor Activity. Animals were kept in actophotometer for 3 minutes for acclimatization, followed by 5 minutes of actual recording. The apparatus was placed in a dark, light-sound-attenuated and ventilated testing room. Each animal was observed over a period of $5 \mathrm{~min}$ in a square $(30 \mathrm{~cm})$ closed arena equipped with infrared-lightsensitive photocells using digital photoactometer and values were expressed as counts per 5 min $[14,15]$.

\subsubsection{Measurement of Anxiety}

Mirror Chamber Test. The mirror chamber consisted of a wooden chamber having a mirror cube enclosed within it. The container box was $40 \times 40 \times 30.5 \mathrm{~cm}$. Animals were placed at the distal corner of the mirror chamber at the beginning of the test.
During the 5 min test session, the following parameters were noted: (a) latency to enter the mirror chamber and (b) average time spent per entry in mirror chamber. An anxiogenic response was defined as decreased number of entries and time spent in the mirror chamber [16].

Elevated Plus Maze Test. The elevated plus maze test is described elsewhere. The apparatus comprises of two open arms $(35 \mathrm{~cm} \times 5 \mathrm{~cm})$ and two closed arms $(30 \mathrm{~cm} \times 5 \mathrm{~cm} \times 15 \mathrm{~cm})$ that extend from a common central platform $(5 \mathrm{~cm} \times 5 \mathrm{~cm})$. The floor and walls of the closed arms are wooden and painted black. The entire maze is elevated to height of $50 \mathrm{~cm}$ above the floor level. Mice of 18-22 g weight were housed in pair for 10 days prior to testing in the apparatus. During this time animals were handled by the investigator on alternate days to reduce stress; each group consists of 10 animals each.

On the 15th day after immobilization stress, each mouse was placed in the center of the maze facing one of the open arms. During a 5-minute test period the following measures were taken: the number of entries into and time spent in the open and the closed arms and time spent in central zone and rearing. The procedure was conducted preferably in a soundattenuated room $[16,17]$.

2.6. Biochemical Parameters. All the animals were sacrificed by decapitation on the same day immediately after behavioral assessents. The brains were removed, rinsed in isotonic saline, and weighed. $10 \%(\mathrm{w} / \mathrm{v})$ tissue homogenates were prepared with $0.1 \mathrm{M}$ phosphate buffer ( $\mathrm{pH}$ 7.4). The postnuclear fractions were obtained by centrifugation of the homogenate at $12000 \times \mathrm{g}$ for $20 \mathrm{~min}$ at $4^{\circ} \mathrm{C}$.

2.6.1. Lipid Peroxidation Assay. The quantitative measurement of lipid peroxidation in the whole brain was assessed as per the method of Wills [18].

The amount of malondialdehyde formed was measured by the reaction with thiobarbituric acid at $532 \mathrm{~nm}$ using Perkin Elmer lambda 20 spectrophotometer. The results were expressed as nanomol of malondialdehyde per mg protein using the molar extinction coefficient of chromophore $\left(1.56 \times 105 \mathrm{M}^{-1} \mathrm{~cm}^{-1}\right)$.

2.6.2. Estimation of Reduced Glutathione. Reduced glutathione (GSH) in the brain was estimated according to the method of Ellman [19]. A $1.0 \mathrm{~mL}$ of homogenate was precipitated with $1.0 \mathrm{~mL}$ of $4 \%$ sulfosalicylic acid by keeping the mixture at $4^{\circ} \mathrm{C}$ for $1 \mathrm{~h}$, and samples were immediately centrifuged at $12000 \times \mathrm{g}$ for $15 \mathrm{~min}$ at $4^{\circ} \mathrm{C}$. The assay mixture contains $0.1 \mathrm{~mL}$ of supernatant, $2.7 \mathrm{~mL}$ of phosphate buffer of $\mathrm{pH} 8.0$, and $0.2 \mathrm{~mL}$ of $0.01 \mathrm{M}$ dithio-bis-nitrobenzoic acid (DTNB). The absorbance of the reaction product was immediately measured at $412 \mathrm{~nm}$ using Perkin Elmer lambda 20 spectrophotometer. The results were expressed as micromole GSH per mg protein.

2.6.3. Nitrite Estimation. Nitrite is the stable end product of nitric oxide (NO) in the living system. Accumulation of nitrite was measured in cell free supernatants from brain 


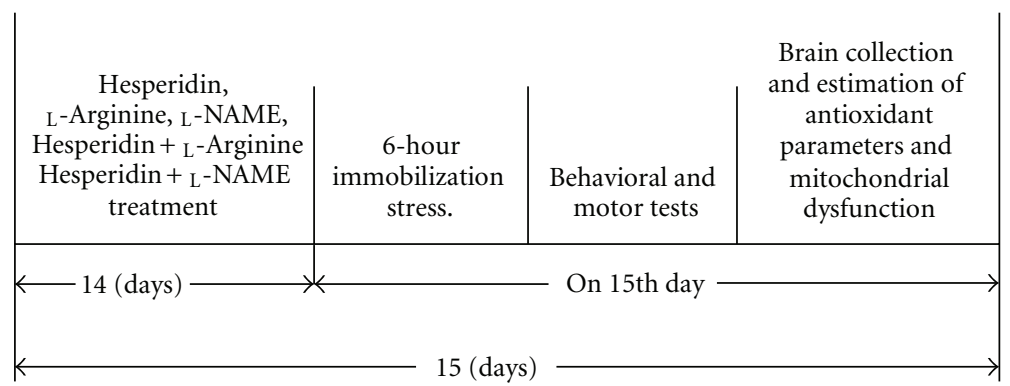

FIGURE 1: Illustration of the protocol used for the study.

homogenates by spectrophotometer assay based on Greiss reagent 15 ( $1 \%$ sulphanilamide/0.1\% naphthylethylenediamine dihydrochloride $2.5 \%$ phosphoric acid) and incubated at room temperature for $10 \mathrm{~min}$ to yield a chromophore. Absorbance was measured at $543 \mathrm{~nm}$ spectrophotometrically.

The nitrite concentration was calculated from a standard curve using sodium nitrite as standard and expressed as micromolar nitrite per $\mathrm{mL}$ homogenate [20].

2.6.4. Protein Estimation. The protein content was measured according to the method of Lowry et al. using bovine serum albumin as standard [21].

2.6.5. Catalase Estimation. Catalase activity was assayed by the method of Luck [22], wherein the breakdown of hydrogen peroxide $\left(\mathrm{H}_{2} \mathrm{O}_{2}\right)$ was measured at $240 \mathrm{~nm}$. Briefly, the assay mixture consisted of $3 \mathrm{~mL}$ of $\mathrm{H}_{2} \mathrm{O}_{2}$ in phosphate buffer and $0.05 \mathrm{~mL}$ of supernatant of tissue homogenate (10\%), and the change in absorbance was recorded at $240 \mathrm{~nm}$. The results were expressed as micromole $\mathrm{H}_{2} \mathrm{O}_{2}$ decomposed per mg of protein/min.

\subsection{Mitochondrial Complex Estimation}

2.7.1. Isolation of Rat Brain Mitochondria. Rat brain mitochondria were isolated by the method of Berman and Hastings [23]. The striatum regions were homogenized in isolation buffer with EGTA (215 mM Mannitol, $75 \mathrm{mM}$ sucrose, 0.1\% BSA, $20 \mathrm{mM}$ HEPES, and $1 \mathrm{mM}$ EGTA, pH 7.2).

Homogenates were centrifuged at $13,000 \mathrm{~g}$ for $5 \mathrm{~min}$ at $4^{\circ} \mathrm{C}$. Pellet was resuspended in isolation buffer with EGTA and spun again at $13,000 \mathrm{~g}$ for $5 \mathrm{~min}$. The resulting supernatants were transferred to new tubes and topped off with isolation buffer with EGTA and again spun at 13,000 $\mathrm{g}$ for 10 min. Pellets containing pure mitochondria were resuspended in isolation buffer without EGTA.

2.7.2. NADH Dehydrogenase Activity. NADH dehydrogenase activity was measured spectrophotometrically (UVPharmaspec 1700 Shimadzu, Japan) by the method of King and Howard [24]. The method involves catalytic oxidation of $\mathrm{NADH}$ to $\mathrm{NAD}^{+}$with subsequent reduction of cytochrome C.
2.7.3. Succinate Dehydrogenase (SDH) Activity. Succinate Dehydrogenase (SDH) activity was measured spectrophotometrically (UV-Pharmaspec 1700 Shimadzu, Japan) according to King [25]. The method involves oxidation of succinate by an artificial electron acceptor, potassium ferricyanide.

2.7.4. MTT (Mitochondrial Redox Activity) Assay. The method employed in the present study is based on the in vitro studies to evaluate mitochondrial redox activity through the conversion of MTT tetrazolium salt to formazan crystals by mitochondrial respiratory chain reactions in isolated mitochondria by the method of Liu et al. [26]. The absorbance of the resulting medium was measured by an ELISA reader at $580 \mathrm{~nm}$ wavelength.

2.7.5. Cytochrome Oxidase Activity. Cytochrome oxidase activity was assayed according to the method of Sottocasa et al. in striatal mitochondria [27].

2.8. Statistical Analysis. All the values are expressed as mean \pm SEM. The data were analyzed by using one-way analysis of variance (ANOVA) followed by Tukey's test. $P<0.05$ was considered statistically significant.

\section{Results}

3.1. Behavioral Assessments. The naïve animals showed consistent and stable locomotor activity and anxiety-like behavior. The $6 \mathrm{~h}$ acute immobilization stress has significantly reduced the locomotor activity (as indicated by decreased ambulatory movements) and induced anxiety-like behaviors (delayed latency to enter the mirror chamber, decreased number of entries and time spent in the mirror chamber, and decreased number of entries and time spent in open arm in elevated plus maze test) as compared to the unstressed (naïve) group $(P<0.05)$ (Figures $2,3,4,5$, and 6$)$. Fourteen days of Hesperidin $(50$ and $100 \mathrm{mg} / \mathrm{kg})(P<0.05$ and $P<$ 0.01 ) pretreatment had significantly inhibited the anxietylike behavior (shortened time latency to enter in mirror chamber, increased average time spent per entry the mirror chamber, and increased number of entries and time spent in open arm in elevated plus maze test) and improved locomotor activity (increased ambulatory movements) as compared to control (restraint stress) animals. However, Hesperidin 


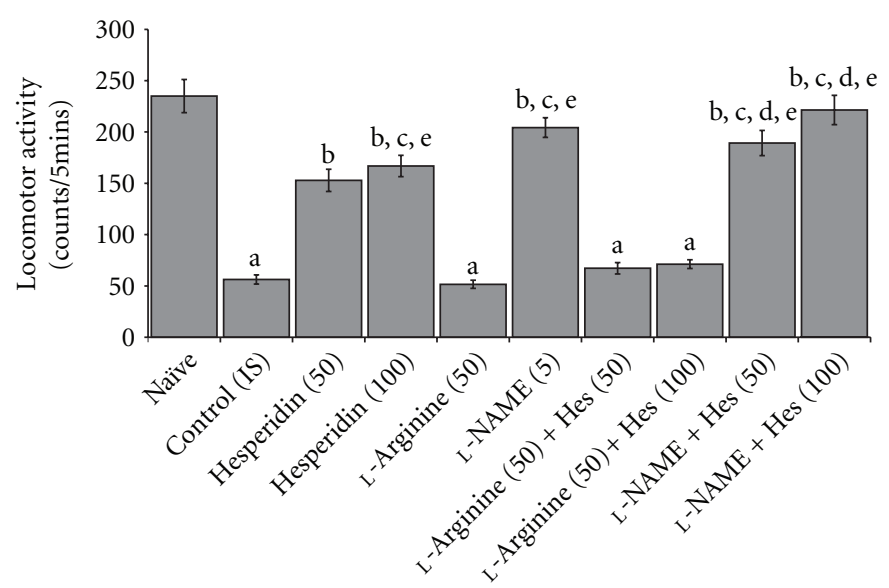

FIGURE 2: Effect of Hesperidin on immobilization-stress-induced altered locomotor activity. IS: immobilization stress, Hes: Hesperidin, and pr: protein, all the values are expressed as mean \pm SEM. ${ }^{a} P<0.05$ compared to naïve, ${ }^{b} P<0.05$ compared to control (IS), ${ }^{c} P<0.001$ compared to Hesperidin (50), d $P<0.05$ compared to Hesperidin-100, and ${ }^{\mathrm{e}} P<0.05$ compared to L-arginine (50).

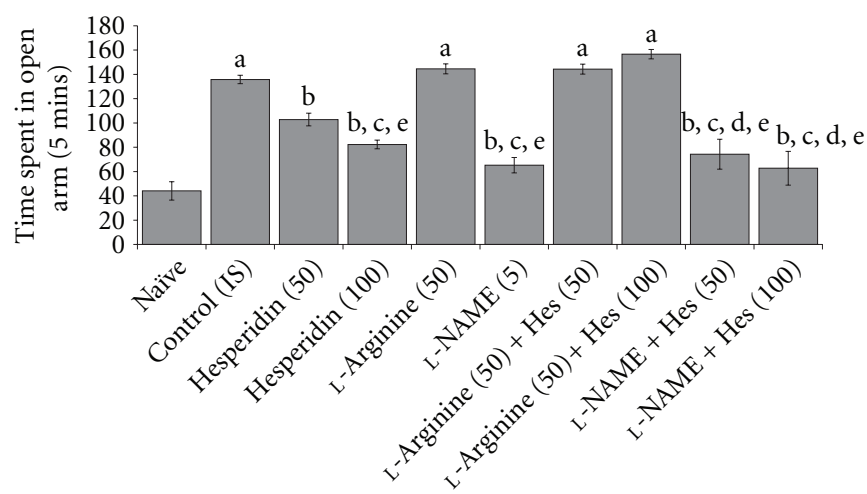

FIGURE 3: Effect of Hesperidin on immobilization-stress-induced anxiety-like behavior in elevated plus maze test (time spent in open arm). IS: immobilization stress, Hes: Hesperidin, and pr: protein, all the values are expressed as mean \pm SEM. ${ }^{\mathrm{a}} P<0.05$ compared to naïve, ${ }^{\mathrm{b}} P<$ 0.05 compared to control (IS), ${ }^{\mathrm{c}} P<0.001$ compared to Hesperidin (50), ${ }^{\mathrm{d}} P<0.05$ compared to Hesperidin-100, and ${ }^{\mathrm{e}} P<0.05$ compared to L-arginine (50).

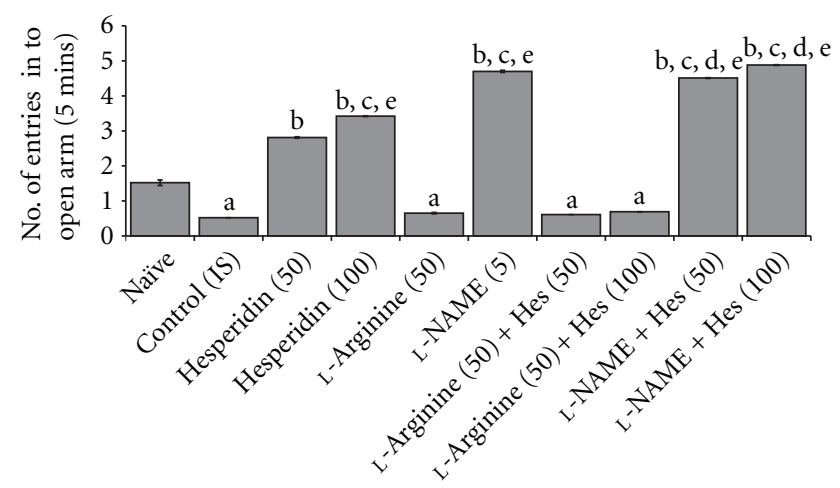

Figure 4: Effect of Hesperidin on immobilization-stress-induced anxiety-like behavior in Elevated plus maze test (No. of entries in to open arm). IS: immobilization stress, Hes: Hesperidin, and pr: protein, all the values are expressed as mean \pm SEM. ${ }^{a} P<0.05$ compared to naïve, ${ }^{b} P<0.05$ compared to control (IS), ${ }^{c} P<0.001$ compared to Hesperidin (50), ${ }^{\mathrm{d}} P<0.05$ compared to Hesperidin100 , and ${ }^{\mathrm{e}} P<0.05$ compared to L-arginine (50). treatment could not restore the performances of stressed mice to the levels of naive group.

Pretreatment with L-arginine ( $50 \mathrm{mg} / \mathrm{kg}$, ip), nitric oxide precursor, produced significant anxiety-like behavior on actophotometer (Figure 2), elevated plus maze (Figures 3 and 4 ), and mirror chamber tests (Figures 5 and 6 ) as compared to naive $(P<0.05)$. In addition, $\mathrm{L}$-arginine $(50 \mathrm{mg} / \mathrm{kg}$, i.p. $)$ treatment has reversed the protective effect of Hesperidin (50 and $100 \mathrm{mg} / \mathrm{kg}$ ) (in all the behavioural tasks) as compared to Hesperidin per se $(P<0.05)$. L-NAME $(5 \mathrm{mg} / \mathrm{kg}$, i.p. $)$, a nitric oxide synthase inhibitor, did not produce any significant effect on actophotometer, elevated plus maze, and mirror chamber tests as compared to control (IS) $(P<0.05)$. However, L-NAME ( $5 \mathrm{mg} / \mathrm{kg}$, i.p.) given in combination with Hesperidin $(50$ and $100 \mathrm{mg} / \mathrm{kg})$ potentiated the protective effect of Hesperidin (increased ambulatory movements, decreased latency to enter the mirror chamber, increased number of entries and time spent in the mirror chamber, and increased number of entries and time spent in open arm in elevated plus maze test) as compared to their effect per se $(P<0.05)$ (Figures 2, 3, 4, 5, and 6). 


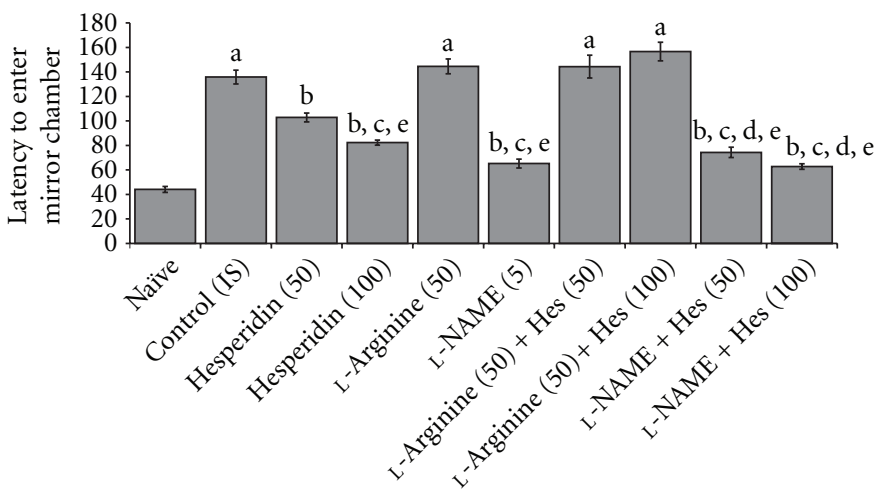

FIGURE 5: Effect of Hesperidin on immobilisation stress induced anxiety-like behavior in mirror chamber test. IS: immobilization stress, Hes: Hesperidin, and pr: protein, all the values are expressed as mean \pm SEM. ${ }^{\text {a }} P<0.05$ compared to naïve, ${ }^{b} P<0.05$ compared to control (IS), ${ }^{c} P<0.001$ compared to Hesperidin (50), ${ }^{\mathrm{d}} P<0.05$ compared to Hesperidin-100, and ${ }^{\mathrm{e}} P<0.05$ compared to $\mathrm{L}$-arginine (50).

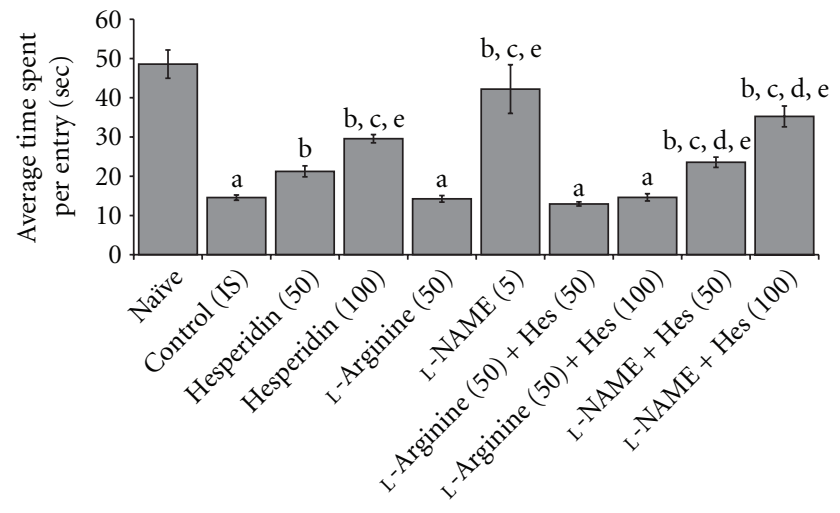

FIGURE 6: Effect of naringin on immobilisation stress induced anxiety-like behaviour in mirror chamber test (No. of entries). IS: immobilization stress, Hes: Hesperidin, and pr: protein, all the values are expressed as mean \pm SEM. ${ }^{a} P<0.05$ compared to naïve, ${ }^{\mathrm{b}} P<0.05$ compared to control (IS), ${ }^{\mathrm{c}} P<0.001$ compared to Hesperidin (50), ${ }^{\mathrm{d}} P<0.05$ compared to Hesperidin-100, and ${ }^{\mathrm{e}} P<$ 0.05 compared to L-arginine (50).

In conclusion, pretreatment with Hesperidin (50 and $100 \mathrm{mg} / \mathrm{kg}$ ) offered significant protection against acute immobilization-stress-induced behavioral and oxidative damage and possible mechanism of action involves modulation of nitric oxide pathway.

3.2. Biochemical Measurements. $6 \mathrm{~h}$ acute immobilization stress has significantly increased the malondialdehyde (MDA) and nitrite concentration and depleted reduced glutathione (GSH) and catalase activity as compared to unstressed (naïve) animals. Fourteen days of pretreatment with Hesperidin $(50$ and $100 \mathrm{mg} / \mathrm{kg})(P<0.05$ and $P<0.01)$ significantly attenuated the rise in MDA and nitrite concentration and caused restoration of GSH and catalase activity as compared to the control (immobilization stress) group $(P<0.05)$ (Table 1$)$.

Treatment with Hesperidin (50 and $100 \mathrm{mg} / \mathrm{kg}$ ) significantly attenuated elevated lipid peroxidation nitrite activity, restored reduced glutathione and catalase activity as compared to control (IS) $(P<0.05)$. Pretreatment with L-arginine $(50 \mathrm{mg} / \mathrm{kg}$, ip) significantly increased lipid peroxidation and nitrite levels as compared to control (IS) $(P<0.05)$ (Table 1).

A combination of $\mathrm{L}$-arginine $(50 \mathrm{mg} / \mathrm{kg}$, i.p.) and pretreatment with Hesperidin (50 and $100 \mathrm{mg} / \mathrm{kg}$ ) reversed the neuroprotective effect of Hesperidin (50 and $100 \mathrm{mg} / \mathrm{kg}$ ) on lipid peroxidation, nitrite activity, reduced glutathione, and catalase activity as compared to their effect per se $(P<0.05)$ (Table 1). L-NAME $(5 \mathrm{mg} / \mathrm{kg}$, ip) per se did not produce any significant effect on oxidative stress parameters as compared to control (IS) $(P<0.05)$. Furthermore, combination of $\mathrm{L}-$ NAME $(5 \mathrm{mg} / \mathrm{kg}$, i.p.) pretreatment with Hesperidin (50 and $100 \mathrm{mg} / \mathrm{kg}$ ) caused further attenuation of lipid peroxidation, nitrite activity and restored the reduced glutathione levels and catalase activity, which was significant as compared to their effect per se $(P<0.05)$ (Table 1$)$.

3.3. Effect of Hesperidin on Mitochondrial Enzyme Complexes (I, II, and IV) in Immobilization-Stress-Induced Animals. There were no significant alterations in mitochondrial enzyme complexes-I, II, IV and mitochondrial redox activity of naïve group. However, $6 \mathrm{~h}$ of immobilization stress has significantly impaired the mitochondrial complexes I (NADH dehydrogenase), II (succinate dehydrogenase), and IV (cytochrome oxidase) enzyme activity as well as mitochondrial redox activity in the immobilization stress (IS) control group as compared to the naïve group (Figure 7). Pretreatment with Hesperidin $(100 \mathrm{mg} / \mathrm{kg})(P<0.01)$ for fourteen days has significantly restored the alterations in mitochondrial enzyme complex activities and mitochondrial redox activity as compared to the IS control group, while pretreatment with Hesperidin $(50 \mathrm{mg} / \mathrm{kg})(P<0.05)$ alone has moderately restored the alterations in mitochondrial enzyme complexes activities and mitochondrial redox activity when compared to control (IS).

Pretreatment with L-arginine ( $50 \mathrm{mg} / \mathrm{kg}$, ip) significantly increased lipid peroxidation and nitrite levels as compared to control (IS) $(P<0.05)$. A combination of $\mathrm{L}$-arginine 
TABLE 1: Effects of Hesperidin on immobilization-stress-induced altered oxidative and biochemical parameters in mice (percentage of naïve in parentheses).

\begin{tabular}{|c|c|c|c|c|}
\hline Treatment & $\begin{array}{c}\text { Reduced GSH } \\
(\mu \text { mole GSH/mg pr })\end{array}$ & $\begin{array}{c}\text { LPO } \\
(n \text { moles of } \mathrm{MDA} / \mathrm{mg} \mathrm{pr})\end{array}$ & $\begin{array}{c}\text { Catalase } \\
\left(\mu \text { mole of } \mathrm{H}_{2} \mathrm{O}_{2} / \mathrm{min} / \mathrm{mg} \mathrm{pr}\right)\end{array}$ & Nitrite $(\mu \mathrm{g} / \mathrm{mL})$ \\
\hline Naïve & $0.094 \pm 0.004(100)$ & $0.120 \pm 0.003(100)$ & $0.806 \pm 0.005(100)$ & $261.3 \pm 9.4(100)$ \\
\hline Control (IS) & $0.014 \pm 0.004(14.89)^{\mathrm{a}}$ & $0.634 \pm 0.004(674.46)^{\mathrm{a}}$ & $0.141 \pm 0.01(17.49)^{\mathrm{a}}$ & $686.4 \pm 21.5(262.68)^{\mathrm{a}}$ \\
\hline Hes-50 & $0.038 \pm 0.003(40.42)^{\mathrm{b}}$ & $0.462 \pm 0.004(491.48)^{\mathrm{b}}$ & $0.421 \pm 0.002(52.23)^{\mathrm{b}}$ & $425.8 \pm 15.2(162.95)^{\mathrm{b}}$ \\
\hline Hes- 100 & $0.061 \pm 0.004(64.89)^{\mathrm{b}, \mathrm{c}, \mathrm{e}}$ & $0.243 \pm 0.006(258.51)^{\mathrm{b}, \mathrm{c}, \mathrm{e}}$ & $0.502 \pm 0.001(62.28)^{\mathrm{b}, \mathrm{c}, \mathrm{e}}$ & $341.6 \pm 19.4(130.73)^{\mathrm{b}, \mathrm{c}, \mathrm{e}}$ \\
\hline L-Arginine (50) & $0.013 \pm 0.005(13.82)^{\mathrm{a}}$ & $0.619 \pm 0.007(658.51)^{\mathrm{a}}$ & $0.125 \pm 0.003(15.51)^{\mathrm{a}}$ & $694.9 \pm 16.2(265.93)^{\mathrm{a}}$ \\
\hline L-NAME (5) & $0.095 \pm 0.002(101.06)^{\mathrm{b}, \mathrm{c}, \mathrm{d}, \mathrm{e}}$ & $0.129 \pm 0.001(137.23)^{\mathrm{b}, \mathrm{c}, \mathrm{d}, \mathrm{e}}$ & $0.785 \pm 0.001(97.39)^{\mathrm{b}, \mathrm{c}, \mathrm{d}, \mathrm{e}}$ & $260.51 \pm 17.5(119.59)^{\mathrm{b}, \mathrm{c}, \mathrm{d}, \mathrm{e}}$ \\
\hline $\begin{array}{l}\text { L-Arginine }(50)+\text { Hes } \\
(50)\end{array}$ & $0.016 \pm 0.003(17.02)^{a}$ & $0.597 \pm 0.003(635.10)^{\mathrm{a}}$ & $0.135 \pm 0.005(16.75)^{\mathrm{a}}$ & $668.2 \pm 23.2(255.72)^{\mathrm{a}}$ \\
\hline $\begin{array}{l}\text { L-Arginine }(50)+\text { Hes } \\
(100)\end{array}$ & $0.019 \pm 0.004(20.21)^{\mathrm{a}}$ & $0.588 \pm 0.006(625.53)^{\mathrm{a}}$ & $0.142 \pm 0.003(17.62)^{\mathrm{a}}$ & $657.6 \pm 15.5(251.66)^{\mathrm{a}}$ \\
\hline $\begin{array}{l}\text { L-NAME }(5)+\text { Hes } \\
(50)\end{array}$ & $0.096 \pm 0.003(102.12)^{\mathrm{b}, \mathrm{c}, \mathrm{d}, \mathrm{e}}$ & $0.120 \pm 0.004(127.6)^{\mathrm{b}, \mathrm{c}, \mathrm{d}, \mathrm{e}}$ & $0.795 \pm 0.004(98.64)^{\mathrm{b}, \mathrm{c}, \mathrm{d}, \mathrm{e}}$ & $294.8 \pm 14.4(112.82)^{\mathrm{b}, \mathrm{c}, \mathrm{d}, \mathrm{e}}$ \\
\hline $\begin{array}{l}\text { L-NAME }(5)+\text { Hes } \\
(100)\end{array}$ & $0.108 \pm 0.005(114.89)^{\mathrm{b}, \mathrm{c}, \mathrm{d}, \mathrm{e}}$ & $0.109 \pm 0.004(115.9)^{\mathrm{b}, \mathrm{c}, \mathrm{d}, \mathrm{e}}$ & $0.816 \pm 0.003(101.24)^{\mathrm{b}, \mathrm{c}, \mathrm{d}, \mathrm{e}, \mathrm{f}}$ & $272.2 \pm 19.5(104.17)^{\mathrm{b}, \mathrm{c}, \mathrm{d}, \mathrm{e}}$ \\
\hline
\end{tabular}

IS: immobilization stress, Hes: Hesperidin, and pr: protein, all the values are expressed as mean \pm SEM. ${ }^{\mathrm{a}} P<0.05$ compared to naïve, ${ }^{\mathrm{b}} P<0.05$ compared to control (IS), ${ }^{\mathrm{c} P}<0.001$ compared to Hesperidin (50), ${ }^{\mathrm{d}} P<0.05$ compared to Hesperidin- 100 , and ${ }^{\mathrm{e}} P<0.05$ compared to L-arginine (50).

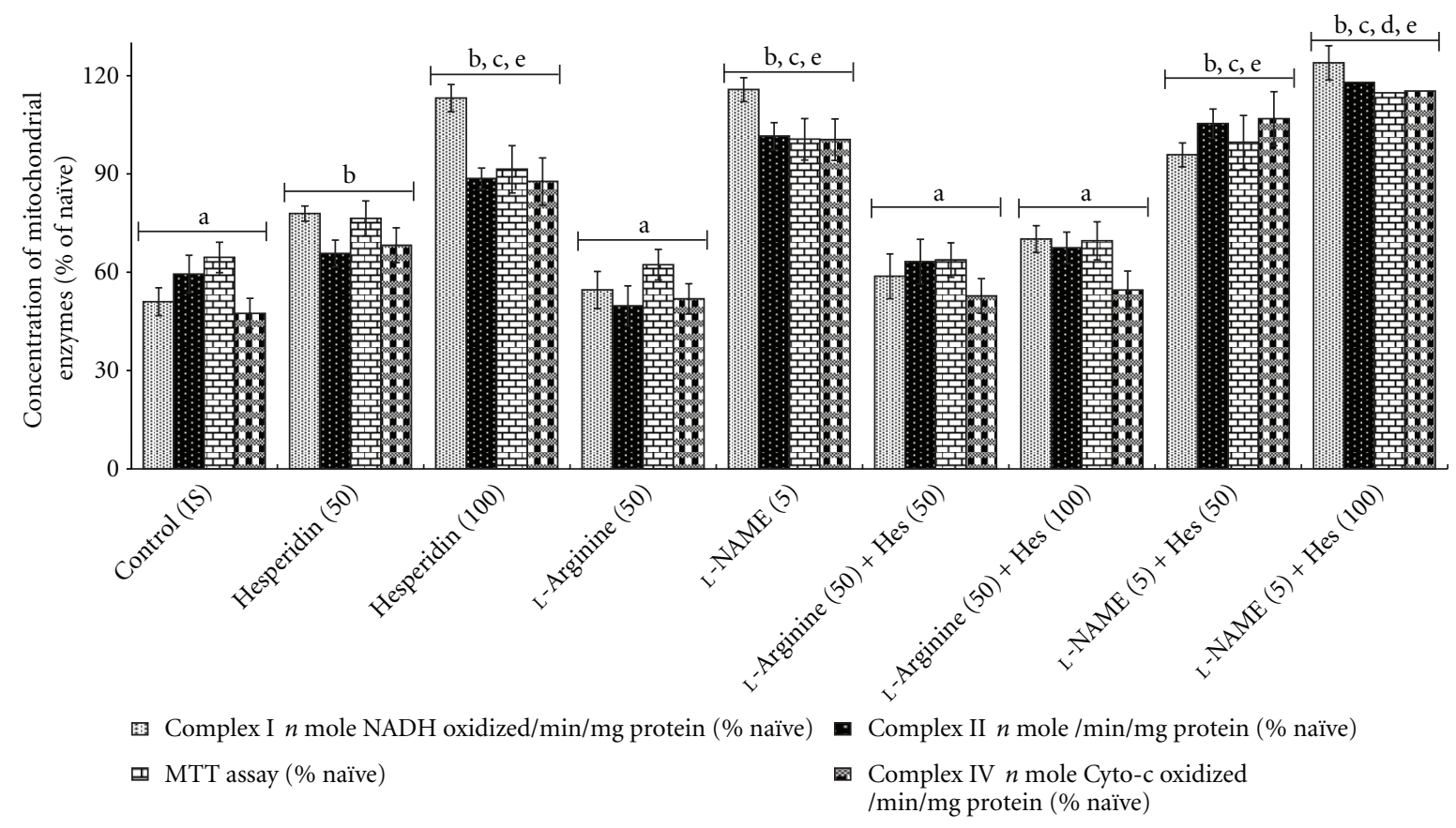

FIGURE 7: Effect of Hesperidin on immobilization stress induced mitochondrial dysfunction in mice (\% naïve). IS: immobilization stress, Hes: Hesperidin, and pr: protein, all the values are expressed as mean \pm SEM (\% of naïve group), ${ }^{a} P<0.05$ compared to naïve, ${ }^{b} P<0.05$ compared to control (IS), ${ }^{\mathrm{C}} P<0.001$ compared to Hesperidin (50), ${ }^{\mathrm{d}} P<0.05$ compared to Hesperidin-100, and ${ }^{\mathrm{e}} P<0.05$ compared to L-arginine (50).

$(50 \mathrm{mg} / \mathrm{kg}$, i.p.) pretreatment with Hesperidin (50 and $100 \mathrm{mg} / \mathrm{kg}$ ) reversed the protective effect of Hesperidin $(50$ and $100 \mathrm{mg} / \mathrm{kg}$ ) on mitochondrial enzyme complex activities and mitochondrial redox activity as compared to their effect per se $(P<0.05)$. L-NAME $(5 \mathrm{mg} / \mathrm{kg}$, ip $)$ per se did not produce any significant effect on normal mitochondrial functions as compared to control (IS) $(P<0.05)$. Furthermore, combination of L-NAME $(5 \mathrm{mg} / \mathrm{kg}$, i.p.) pretreatment with Hesperidin (50 and $100 \mathrm{mg} / \mathrm{kg}$ ) caused further restoration of alterations in mitochondrial enzyme complex activities and mitochondrial redox activity, which was significant as compared to their effect per se $(P<0.05)$. 


\section{Discussion}

Stress is a physical and/or environmental and/or psychological stimulus that is capable of altering the physiological homeostasis of the body, and hence coping up with such stress condition makes it as a crucial determinant in health and disease [28].

Stress activates hypothalamus-pituitary-adrenal axis (HPA) and also causes changes in catecholamine levels and thereby influences several neurological functions at both central and peripheral levels. Any kind of stress influences brain functions by causing long-term changes in the multiple neural systems, which leads to various neurodegenerative disorders [29]. Exposure to chronic immobilization stress in animals and psychological stress in human has implicated pathophysiology of anxiety and mood disorders [30]. Acute immobilization stress has been reported to influence motor activity, anxiety-like behavior, and depression-like behaviors in the animals [31]. In the present study, $6 \mathrm{~h}$ immobilization stress caused significant anxiety-like behavior and impaired motor activity, indicating stress-induced neurobehavioral alterations and neurobehavioral alterations due to acute and chronic stress has already been reported in the literature [31]. In the present study observed behavioral changes might be due to alteration in the brain regions controlling motor activity and anxiety-like behavior, while impaired motor activity could be due to stress-induced depression.

In the present study, Hesperidin (50 and $100 \mathrm{mg} / \mathrm{kg}$, p.o.) offered significant protection against immobilization stress induced neurobehavioral alterations (locomotor activity and anxiety-like behavior) and oxidative damage to the brain, suggesting its neuroprotective effect against stressful conditions.

Immobilization stress causes drastic increase in the production of reactive oxygen species and consequent oxidative damage with a proportionate decrease in in vivo antioxidant defense [32]. Oxidative stress causes cellular damage and accelerates neurodegeneration by inducing the reactive oxygen species (ROS) that oxidize vital cellular components such as lipids, proteins, and DNA [33]. In the present study, $6 \mathrm{~h}$ immobilized stress caused significant oxidative damage as indicated by the rise in lipid peroxidation, nitrite concentration and depleted reduced GSH and catalase activity. Pretreatment with Hesperidin $(50$ and $100 \mathrm{mg} / \mathrm{kg}$ ) has significantly attenuated the lipid peroxidation and nitrite concentration and restored GSH and catalase activity suggesting its antioxidant-like effect. Supporting our study, a clinical trial also indicated raised level of MDA in patients with affective disorders [34]. Besides, it is been demonstrated that immobilization stress induces expression of the inducible isoform of NO synthase (NOS-2) in rat brain [35] and leading to formation of large amount of nitrogen reactive species that may account for the oxidation of cellular components [36].

In accordance with the above findings, in the present study, Hesperidin elevated the antioxidant enzyme defense system against immobilization stress-induced oxidative damage. The possible mechanism behind the protective effect of Hesperidin is inhibition of NO synthesis in the brain.
Mitochondria are considered as a major source of ROS, which include superoxide anion $\left({ }^{\circ} \mathrm{O}_{2}\right), \mathrm{H}_{2} \mathrm{O}_{2}$, and the hydroxyl free radical $\left({ }^{\bullet} \mathrm{OH}\right)$. The evidence suggests that oxidative stress-induced damage to mitochondria is a major cause of brain cell death [37]. Damage in various mitochondrial complexes was measured in terms of respiratory enzyme oxidative properties and our findings in the present study are in accordance with the literature reports. Major dysfunctions in complexes I and II and minor dysfunction in complexes III and IV were observed when compared to their respective control groups.

Hesperidin (50 and $100 \mathrm{mg} / \mathrm{kg}$ ) pretreatment has significantly restored the mitochondrial enzyme activity suggesting its role in mitochondrial enzyme functions. Further, L-arginine pretreatment with Hesperidin (50 and $100 \mathrm{mg} / \mathrm{kg}$ ) caused reversal of Hesperidin protective effect (impairment of mitochondrial enzyme complex), while, L-NAME pretreatment with Hesperidin caused potentiation of its protective effect (restoration of mitochondrial enzyme activity), which further confirms the involvement of nitric oxide mechanism.

\section{Conclusion}

The findings of the present study suggest that Hesperidin (50 and $100 \mathrm{mg} / \mathrm{kg}$ ) is a bioflavonoid found to ameliorate the immobilization-stress-induced oxidative-nitrergic stress, biochemical alterations, mitochondrial dysfunction, and associated neurobehavioral alterations in mice and also suggest the involvement of nitrergic pathway in the protective effect of Hesperidin against immobilization-stress-induced neurobehavioral alterations.

\section{Conflict of Interests}

The authors report no conflicts of interests.

\section{References}

[1] S. McIlroy and D. Craig, "Neurobiology and genetics of behavioural syndromes of Alzheimer's disease," Current Alzheimer Research, vol. 1, no. 2, pp. 135-142, 2004.

[2] F. U. Fontella, I. R. Siqueira, A. P. S. Vasconcellos, A. S. Tabajara, C. A. Netto, and C. Dalmaz, "Repeated restraint stress induces oxidative damage in rat hippocampus," Neurochemical Research, vol. 30, no. 1, pp. 105-111, 2005.

[3] O. Firuzi and D. Praticò, "Coxibs and Alzheimer's disease: should they stay or should they go?" Annals of Neurology, vol. 59, no. 2, pp. 219-228, 2006.

[4] J. Liu, X. Wang, M. K. Shigenaga, H. C. Yeo, A. Mori, and B. N. Ames, "Restraint stress causes oxidative damage to lipid, protein, and DNA in the brains of rats," FASEB Journal, vol. 10, no. 13, pp. 1532-1538, 1996.

[5] B. Halliwell and J. M. C. Cutteridge, "Oxygen radicals and the nervous system," Trends in Neurosciences, vol. 8, no. 1, pp. 2226, 1985.

[6] D. J. Bristow and D. S. Holmes, "Cortisol levels and anxietyrelated behaviors in cattle," Physiology and Behavior, vol. 90, no. 4, pp. 626-628, 2007. 
[7] R. Goyal and A. Kumar, "Protective effect of alprazolam in acute immobilization stress-induced certain behavioral and biochemical alterations in mice," Pharmacological Reports, vol. 59, no. 3, pp. 284-290, 2007.

[8] J. LeDoux, "Fear and the brain: where have we been, and where are we going?" Biological Psychiatry, vol. 44, no. 12, pp. 1229$1238,1998$.

[9] M. Davis and C. Shi, "The extended amygdala: are the central nucleus of the amygdala and the bed nucleus of the stria terminalis differentially involved in fear versus anxiety," Annals of the New York Academy of Sciences, vol. 877, pp. 281-291, 1999.

[10] P. G. Henke and A. Ray, "Stress ulcer modulation by limbic system structures," Acta Physiologica Hungarica, vol. 80, no. 14, pp. 117-125, 1992.

[11] G. R. M. M. Haenen, J. B. G. Paquay, R. E. M. Korthouwer, and A. Bast, "Peroxynitrite scavenging by flavonoids," Biochemical and Biophysical Research Communications, vol. 236, no. 3, pp. 591-593, 1997.

[12] I. Maridonneau-Parini, P. Braquet, and R. P. Garay, "Heterogenous effect of flavonoids on $\mathrm{K}+$ loss and lipid peroxidation induced by oxygen-free radicals in human red cells," Pharmacological Research Communications, vol. 18, no. 1, pp. 61-72, 1986.

[13] T. K. Sur and D. Bhattacharyya, "The effect of Panax ginseng and diazepam on brain and hypothalamic 5- hydroxytryptamine during stress," Indian Journal of Pharmacology, vol. 29, no. 5, pp. 318-321, 1997.

[14] G. L. Viswanatha, K. Nandakumar, H. Shylaja, C. Ramesh, and R. Srinath, "Anxiolytic and anticonvulsant activity of Cedrus deodara in rodents," Journal of Pharmaceutical Research and Health Care, vol. 1, no. 2, pp. 217-239, 2009.

[15] V. Alagarsamy, A. Thangathiruppathy, S. Mandal et al., "Pharmacological evaluation of 2 -substituted $(1,3,4)$ thiadiazolo quinazolines," Indian Journal of Pharmaceutical Sciences, vol. 68, no. 1, pp. 108-111, 2006.

[16] S. K. Kulkarni and D. S. Reddy, "Animal behavior models for testing antianxiety," Methods \& Findings in Experimental \& Clinical Pharmacology, vol. 18, no. 3, pp. 219-230, 1996.

[17] S. Hogg, "A review of the validity and variability of the elevated plus-maze as an animal model of anxiety," Pharmacology Biochemistry and Behavior, vol. 54, no. 1, pp. 21-30, 1996.

[18] E. D. Wills, "Mechanisms of lipid peroxide formation in animal tissues," Biochemical Journal, vol. 99, no. 3, pp. 667-676, 1966.

[19] G. L. Ellman, "Tissue sulfhydryl groups," Archives of Biochemistry and Biophysics, vol. 82, pp. 48670-48677, 1959.

[20] L. C. Green, D. A. Wagner, and J. Glogowski, "Analysis of nitrate, nitrite, and [15N]nitrate in biological fluids," Analytical Biochemistry, vol. 126, no. 1, pp. 131-138, 1982.

[21] O. H. Lowry, N. J. Rosenberg, A. L. Farr, and R. J. Randall, "Protein measurement with the Folin phenol reagent," The Journal of biological chemistry, vol. 193, no. 1, pp. 265-275, 1951.

[22] H. Luck, "Catalase," in Methods of Enzymatic Analysis, H. U. Bergmeyer, Ed., pp. 885-893, Academic Press, New York, NY, USA, 1971.

[23] S. B. Berman and T. G. Hastings, "Dopamine oxidation alters mitochondrial respiration and induces permeability transition in brain mitochondria: implications for Parkinson's disease," Journal of Neurochemistry, vol. 73, no. 3, pp. 1127-1137, 1999.

[24] T. E. King and R. L. Howard, "Preparations and properties of soluble NADH dehydrogenases from cardiac muscle," Methods in Enzymology, vol. 10, pp. 275-294, 1967.
[25] T. E. King, "Preparation of succinate dehydrogenase and reconstitution of succinate oxidase," Methods in Enzymology, vol. 10, pp. 322-331, 1967.

[26] Y. Liu, D. A. Peterson, H. Kimura, and D. Schubert, "Mechanism of cellular 3-(4,5-dimethylthiazol-2-yl)-2,5- diphenyltetrazolium bromide (MTT) reduction," Journal of Neurochemistry, vol. 69, no. 2, pp. 581-593, 1997.

[27] G. L. Sottocasa, B. Kuylenstierna, L. Ernster, and A. Bergstrand, "An electron-transport system associated with the outer membrane of liver mitochondria. A biochemical and morphological study," Journal of Cell Biology, vol. 32, no. 2, pp. 415-438, 1967.

[28] B. Bohus, J. M. Koolhaas, C. J. Heijnen, and O. De Boer, "Immunological responses to social stress: dependence on social environment and coping abilities," Neuropsychobiology, vol. 28, no. 1-2, pp. 95-99, 1993.

[29] B. S. McEwen, "Protection and damage from acute and chronic stress: allostasis and allostatic overload and relevance to the pathophysiology of psychiatric disorders," Annals of the New York Academy of Sciences, vol. 1032, pp. 1-7, 2004.

[30] A. Walesiuk, E. Trofimiuk, and J. J. Braszko, "Ginkgo biloba normalizes stress- and corticosterone-induced impairment of recall in rats," Pharmacological Research, vol. 53, no. 2, pp. 123-128, 2006.

[31] S. Sevgi, M. Özek, and L. Eroǧlu, "L-NAME prevents anxietylike and depression-like behavior in rats exposed to restraint stress," Methods and Findings in Experimental and Clinical Pharmacology, vol. 28, no. 2, pp. 95-99, 2006.

[32] A. Zafir and N. Banu, "Antioxidant potential of fluoxetine in comparison to Curcuma longa in restraint-stressed rats," European Journal of Pharmacology, vol. 572, no. 1, pp. 23-31, 2007.

[33] F. Marzatico, L. Bertorelli, O. Pansarasa, P. Guallini, C. Torri, and G. Biagini, "Brain oxidative damage following acute immobilization and mild emotional stress," International Journal of Stress Management, vol. 5, no. 4, pp. 223-236, 1998.

[34] M. E. Ozcan, M. Gulec, E. Ozerol, R. Polat, and O. Akyol, "Antioxidant enzyme activities and oxidative stress in affective disorders," International Clinical Psychopharmacology, vol. 19, no. 2, pp. 89-95, 2004.

[35] R. Olivenza, M. A. Moro, I. Lizasoain et al., "Chronic stress induces the expression of inducible nitric oxide synthase in rat brain cortex," Journal of Neurochemistry, vol. 74, no. 2, pp. 785-791, 2000.

[36] L. O. Ángel, M. Salvador, M. E. José et al., "Oxidative and nitrosative stress in the metastatic microenvironment," Cancers, vol. 2, no. 2, pp. 274-304, 2010.

[37] A. Nakai, "Role of mitochondrial permeability transition in the immature brain following intrauterine ischemia," Journal of Nippon Medical School, vol. 74, no. 3, pp. 190-201, 2007. 

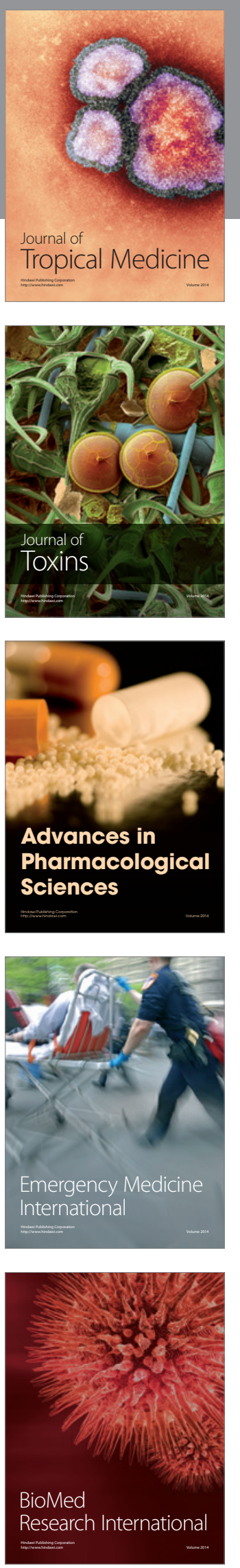
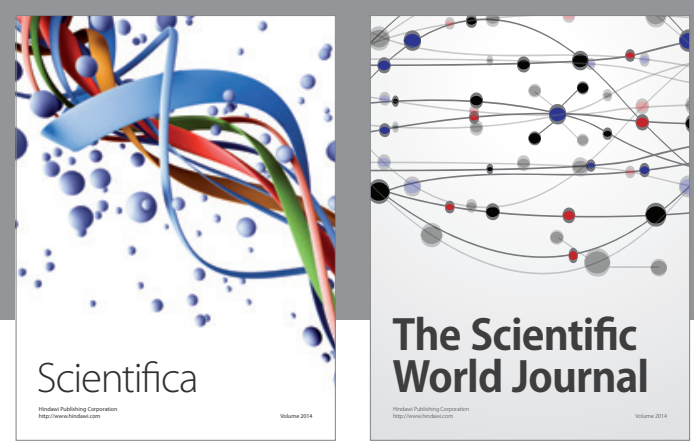

The Scientific World Journal
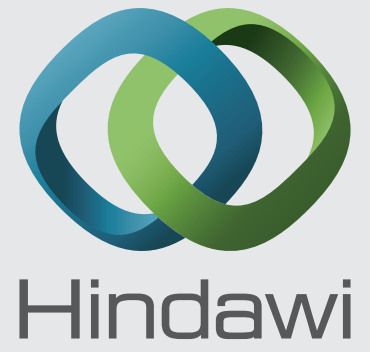

Submit your manuscripts at

http://www.hindawi.com
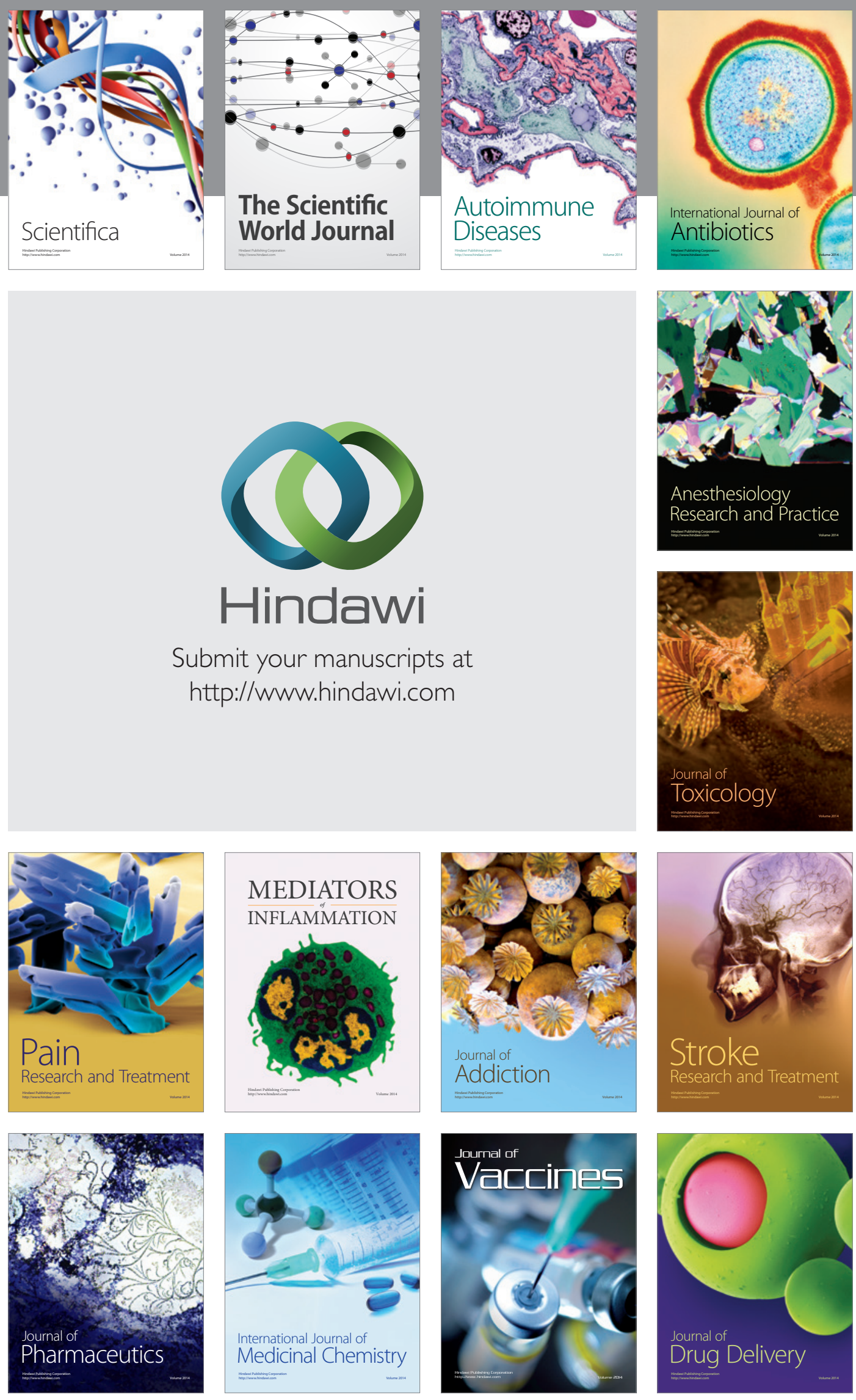